\title{
Governing bodies of sport as knowledge brokers in Sport-for -All communities of practice
}

\author{
Annick Willem ${ }^{\mathrm{a}, *}$, Vassil Girginov ${ }^{\mathrm{b}}$, Kristine Toohey ${ }^{\mathrm{c}}$

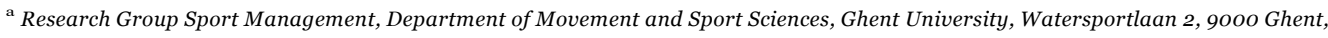 \\ Belgium \\ ${ }^{\mathrm{b}}$ Department of Life Sciences, College of Health and Life Sciences, Brunel University London, Uxbridge, UB8 3 PH, United Kingdom \\ ${ }^{\mathrm{c}}$ Department of Tourism, Sport and Hotel Management, Gold Coast Campus, Griffith University, Parklands Drive, Southport, QLD, 4222 , \\ Australia
}

\section{A R T I C LEIN F O}

\section{Article history:}

Received 15 January 2018

Received in revised form 24 August 2018

Accepted 25 August 2018

Available online 5 September 2018

https://doi.org/10.1016/j.smr.2018.08.005

\section{Keywords:}

Sport-for-A1l

Communities of practice

Sport and development

Knowledge sharing

Governing bodies of sport

\begin{abstract}
A B S T R A C T
Delivering Sport-for-All is a major challenge for sport organizations and policy-makers worldwide. Sport-for-A11 is a practical activity and a knowledge intensive field, characterized by dispersed knowledge creation and sharing processes involving numerous agencies, professionals and volunteers; in other words, it is a community of practice. Communities of practice are vehicles that allow knowledge sharing and creation in intensive and dispersed settings. Learning in communities is enhanced by knowledge brokers, a role typically assumed by governing bodies of sport as part of their formal mandates. In this study, the authors use a community of practice lens to look at Sport-forAll. The authors collected and analyzed data on Sport-for-All communities on the regional (Flanders), national (Australia and England), and international (Sport and Development) level by interviewing key people in each of the communities, and by interrogating virtual knowledge repositories (websites) and public web-based data. Results indicated the existence of Sport-for-All communities of practice with governing bodies of sport acting as brokers in those communities for sharing knowledge, exploration of new ideas, and knowledge creation. However, governing bodies of sport are not strategically exploiting the full potential of online tools to enhance the communities. They ought to focus on supporting the communities by taking a more strategic approach and using new media tools, and let the community of practice standards emerge instead of determining them.
\end{abstract}

\section{Introduction}

Sport-for-All is an umbrella concept encompassing a range of meanings and practices. It reflects an ideology and related institutionalized policies and practices concerned with promoting social justice and equality (Dobbels, Voets, Marlier, De Waegeneer, \& Willem, 2018). It is inherently a developmental enterprise, as by definition any engagement with sport leads to personal, organizational, and social changes (Girginov, 2008). And it is premised on active participation (including access to cognitive and material resources) as a necessary condition for any such changes/benefits to occur (Coalter, 2013). Accordingly, more recent terms, such as sport development and sport for development (Edwards, 2015), do not represent

\footnotetext{
* Corresponding author.

E-mail addresses: annick.willem@ugent.be (A. Willem), vassil.girginov@brunel.ac.uk (V. Girginov), k.toohey@griffith.edu.au (K. Toohey).
} 
new phenomena; rather, they tend to emphasize different aspects of the same Sport-for-All concept and are on a continuum with greater or lesser focus on participation (Hylton \& Totten, 2008). In this paper, we use these terms interchangeably, fitting with the complex, dispersed, and knowledge-intensive character of the field, and the sheer amount of organizations involved.

The range of Sport-for-All providers is wide and varied and includes governmental agencies, non- and-for profit sport, and non-sport organizations, operating at international, national, regional, or local levels (Vos et al., 2011). Thus, Sport-for-All practices are dispersed and involve numerous volunteers and paid staff (Bergsgard, Houlihan, Mangset, Nodland, \& Rommetvedt, 2007) who drive its delivery on a daily basis (Skille, 2008). Moreover, new technological possibilities, combined with greater diversity in Sport-for-All provision, have created a context in which practitioners can interact and shape the field in innovative ways (Girginov \& Hills, 2008; Girginov, Taks, Boucher, \& Holman, 2009).

Apart from these structural dimensions, Sport-for-All is also a knowledge-driven activity, involving both very contextspecific knowledge and generic principles. It seeks to address the complex social problem of encouraging non-active people to engage in sport in a sustainable manner, a process that defies linear thinking assuming a simple relationship between inputs and outcomes. Knowledge is crucial for creating Sport-for-All opportunities, developing programs, and understanding what programs work, for whom, and when (Girginov, Toohey, \& Willem, 2015). Moreover, researchers have also indicated that there are core principles, universally shared concerns, and corresponding practices that are common in all Sport-for-All contexts (Girginov et al., 2015a; Marlier et al., 2015). While the Sport-for-All sector can greatly benefit from developing, storing, and sharing knowledge about participants, policies, programs, and outcomes, Sport-for-All knowledge sharing practices have been challenging due to diverse cultural contexts, agendas, providers, and delivery mechanisms (Girginov et al., 2015a). Lack of knowledge sharing on Sport-for-All has resulted in limited knowledge consolidation and few systematic evidence-based approaches in the field (Girginov, Toohey, \& Willem, 2015).

Several scholars have focused on understanding the non-profit organizations involved in Sport-for-All (e.g., Misener \& Doherty, 2009; Sharpe, 2006) or on Sport-for-All policy development (e.g., Houlihan, 2008; Skille, 2008; Van Tuyckom \& Scheerder, 2010) and sport policy networks (Grix \& Phillpots, 2011; Lin \& Kao, 2016; Phillpots, Grix, \& Quarmby, 2011). However, none of these researchers have specifically considered the knowledge practices of the Sport-for-All community and the role of knowledge brokers in enhancing and facilitating knowledge sharing in the community.

Due to their privileged position and government support, governing bodies of sport in many European countries and Australia have emerged as the focal origination and, consequently, chief coordinator in the Sport-for-All field (Girginov et al., 2015b, 2009). Governing bodies of sport have been actively involved in developing, storing, and sharing Sport-for-All knowledge. The need for better global knowledge sharing and coordination has prompted the emergence of numerous organizations at international level, such as the (Youth) European non-governmental sport organization (Youth ENGSO and ENGSO) and Sportanddev. However, few researchers have studied their role as knowledge brokers (Girginov et al., 2015a) and there is a lack of understanding of the extent to which these organizations are able to enhance learning in Sport-for-All communities and ensure a process of knowledge creation and sharing.

We argue that the concept of community of practice is a potentially useful heuristic tool capable of providing these insights. Communities of practice are characterized by a social space in which a common identity and social interactions allow for the sharing of knowledge (Li et al., 2009). The concept of a community of practice, thus, provides a new analytical device to unpack the pluralistic nature of Sport-for-All and management challenges facing governing bodies of sport in implementing initiatives. Hence, this concept can help in enhancing our knowledge of the Sport-for-All delivery systems, and subsequently its efficacy.

The aims of this paper are threefold to: (a) explore the concept of community of practice as a lens to study Sport-for-All delivery; (b) study empirically the presence and functionality (ability to enhance learning and knowledge sharing processes) of Sport-for-All communities of practice on three levels: regional (Flanders), national (England and Australia), and international (Sport and development); and (c) examine the broker role of leading organizations in the communities at each level, namely of Sport Flanders, Sport England, the Australian Sports Commission, and Sportanddev. To the best of our knowledge, we are the first to focus on community of practice in sport management.

The following section analyses the dispersed nature of delivering Sport-for-All, followed by the conceptualization of a community of practice as an analytical tool for studying sport delivery to address the first aim of the paper. We then describe and analyse the four cases in which we collected primary and secondary data. In the conclusion section, we outline the applicability of the Sport-for-All community of practice. We did not try to investigate the social learning and knowledge creation processes within the community of practice, but instead, focused solely on the knowledge brokers and facilitators in four communities of practice cases and their differences and commonalities with regard to roles, tools, and efforts to develop and enhance standards in Sport-for-All. From a sport management perspective these are the most manageable aspects in Sport-for-All community of practice.

\section{The complex nature of Sport-for-All delivery}

Government organizations have been involved in delivering Sport-for-All through various interventions (Green, 2006), but no single definition of Sport-for-All and of the organizations that need to be involved exists (Skille \& Osteras, 2011). Nonetheless, several researchers have agreed that Sport-for-All requires diverse collaborations (Cousens, Barnes, \& MacLean, 2012; Lindsey, 2006). Cousens and Barnes (2009) and Cousens et al. (2012), for instance, emphasized the highly embedded 
and complex character of Sport-for-All's delivery community and that the numerous formal and informal relationships between organizations and volunteers may inhibit interactions. Skille (2008) argued that policymakers need to understand better how the Scandinavian Sport-for-All operates and that organizations other than elite sport agencies ought to be involved in its delivery. Notwithstanding its diverse nature, a common characteristic of Sport-for-All is the critical role of a central coordinating governing body. Houlihan and Green (2009) explicated that Sport England keeps tight control on the country's Sport-for-All delivery by closely monitoring participation numbers. The same kind of control and co-ordination takes place in Australia and Flanders (Girginov et al., 2015a). What unifies this seemingly wide diversity of policies, practical approaches and agencies are two underlying similarities. The first is an explicit concern with positive Sport-for-All outcomes, and the second is the central role of state actors.

Knowledge is essential in developing and implementing Sport-for-All and involves numerous experts and practitioners (Rowe, 2009). Thus, both as a concept and a practical activity, Sport-for-All is predicated on knowledge. Due to its labour intensive and resource-dependent nature, national or regional sport governing bodies typically control this knowledge (Girginov et al., 2015a). However, these governing bodies of sport are not the sole knowledge creators and certainly not the only promoters of Sport-for-All practices. Thus, there exists a challenge in coordinating the knowledgeflow in the dispersed landscape of Sport-for-All delivery and in enhancing social learning among practitioners. To obtain greater insights into how knowledge about the practices is codified, shared, and diffused in the field, the community of practice lens is used.

\section{Communities of practice}

The notion of a community is not new to the field of knowledge sharing and learning, and was introduced in the 1990 s by Wenger (1998) through the concept of community of practice. Communities of practice are communities involved in an activity led by knowledge brokers who enhance the knowledge and learning processes across the community. Communities of practice are everywhere inside and outside organizations and may cross organizational boundaries (Wenger, 1998). Wenger et al. (2002) defined communities of practice as "groups of people who share a concern, a set of problems, or a passion about a topic, and who deepen their knowledge and expertise in this area by interacting on an ongoing basis" (p. 4).

The concept of community of practice draws from adult learning principles and suggests that all learning is situated in communities of practice (Lave \& Wenger, 1991). To become a member of such a community requires learning, often by apprenticeship and/or socialization (Barley \& Kunda, 2001). Brown and Duguid (1991) suggested that communities of practice are informal and evolving, not limited by organizational boundaries, and can exist in a virtual setting(Ardichvili, 2008).

People belong to a community of practice due to their shared interest and practices, but might not deliberately choose to do so or even realize that they are part of one (Wenger, 1998). A community of practice can be situated on different levels, including global (virtual) worldwide community (e.g., employees of a multinational corporation sharing practices; Kirkman, Cordery, Mathieu, Rosen, \& Kukenberger, 2013), or local, with members all located in a smaller region. Thus, the boundaries of a community of practice are not geographical but determined by a shared concern.

The structural model of a community of practice is made up of three fundamental elements: a domain of knowledge, which defines a set of issues (e.g., sport participation); a community of people who care about this domain; and the shared practice that members are developing to be effective in their domain (Wenger, McDermott, \& Snyder, 2002). Thus, there is a common concern for certain issues as well as identified practices, which makes people feel drawn towards a community of practice.

Wenger (1998) suggested three modes of belonging to a community: engagement, imagination, and alignment. Community members can be engaged to advise each other, and to help and share their expertise. Since a community is not necessarily a well-defined physical structure with formal membership or a fixed location or building, imagination is essential in constructing a community of practice. Members create the image of the community of practice to which they orient themselves. Furthermore, alignment refers to coordinating the community of practice's practices to fit within higher goals. The practices are not just individual initiatives, but align with a higher goal, such as creating opportunities for all to practice sport.

Ayas and Zeniuk (2001) argued that communities of practice have a reflective character. Identifying with the community of practice group and absorbing the culture of the practice are essential elements in the learning processes within the community of practice (Lave \& Wenger, 1991). Common understandings enhances knowledge sharing. Learning the norms, rules, and culture of the community is central in this learning process (Lave \& Wenger, 1991). Communities of practice evolve (Lave \& Wenger, 1991) and their situational character can make it difficult to capture knowledge. Storytelling and narratives help in capturing knowledge (Barley \& Kunda, 2001). Communities of practice need to be sufficiently stable to develop shared understanding and socialization. However, a certain level of turnover in participants is possible without endangering the existence of the community of practice (Li et al., 2009). Although communities of practice are social learning spaces and not management tools, they can be cultivated and even 'managed' by a leader or facilitator (Wenger et a1., 2002). The leader is a highly respected expert who can recruit new members, while the facilitator can be responsible for the activity of the community of practice.

The concept of community of practice has not been without critics. The community of practice perspective is a lens within social learning theory that has been employed to examine a range of social learning settings, such as education and health care (Harris \& Jones, 2010; Kothari, Boyko, Conklin, Stolee, \& Sibbald, 2015). Like other useful theoretical lenses, researchers 
shape the evolution of the concept and criticize its applicability. As a consequence, several authors pointed to the vagueness of the concept of community of practice and the difficulty of clearly distinguishing between it and other groups of interest (Aubry, Müller, \& Glückler, 2011; Li et al., 2009). Li et al. (2009) suggest that the original notion of community of practice evolved from a concept on social learning to a management tool to enhance a group's competitiveness or foster innovation. In the latter case, the community becomes more formal and less of a voluntarily learning process where experts share similar practices.

Aubry et al. (2011) pointed to a management paradox in communities of practice. A strength of communities of practice is that they are self-organized, informal, and emerging groups in which social learning takes place that crosses organizational boundaries. However, as part of the development of (strategic) knowledge management, communities of practice have been utilized as an instrument to enhance the learning capacity of organizations, and to create and capture its knowledge. In this scenario, communities of practice are purposefully managed where leaders and facilitators might deliberately identify and support the communities that only benefit their organization (Wenger \& Snyder, 2000). This instrumental use contradicts the voluntariness and boundary crossing character of communities of practice.

Mintzberg (2009), although not explicitly referring to the concept of community of practice, introduced the notion of "communityship" and suggested that a grouping exists that lies in between collective citizenship and individual leadership. The latter results in a situation in which leaders set the trend, have the knowledge and others would follow. In collective citizenship, a fully dispersed situation exists without leadership. In communityship, a minimum of leadership exists in the form of a community leader who encourages people in a community to contribute (e.g., as is the case for Wikipedia or open source software development). Within communities of practice such leadership exists and might even be necessary to facilitate the knowledge processes in the community. Hence, a community of practice balances between leadership and citizenship.

Communities of practice have potential limitations as they might even inhibit learning when, for example, group thinking and 'not-invented-here' syndromes occur. The strength of a community of practice is at the same time its weaknesses (Wenger, 2010). People are committed to a certain practice and part of that commitment is also to ensure that such practice has status and that a stronger voice is obtained through the community of practice. The same processes that benefit the learning in the communities endangers these communities. "Learning, once successful, is prone to turning into its own enemy" (Wenger, 2010, p. 3). Awareness for silent voices, learning, and feedback loops, openness to newcomers, and a legitimate coordinator or facilitator with the ability to criticize the community are important for a community of practice to avoid becoming self-destructive. Notwithstanding the criticisms, the community of practice concept remains a useful lens to study learning and knowledge sharing practices in the field of Sport-for-All.

\section{Sport-for-all as a community of practice}

Sport-for-All communities of practice can clearly be distinguished from networks such as partnerships (e.g., Cousens \& Barnes, 2009). While partnerships are developed to reach a common goal, communities of practice do not have a common goal but rather a common interest and identity. Communities of practice are thus social learning spaces, not networks, and hence, draw from learning theory and knowledge management concepts. However, literature on communities of practice in a sport management or Sport-for-All context is scarce (Girginov et al., 2015a). Most scholars focusing on communities of practice in a sport context have investigated the role of coaches and coach education (e.g., Culver \& Trudel, 2008; Garner \& Hill, 2017; Mayer, Woulfin, \& Warhol, 2015; Stoszkowski \& Collins, 2014; Stoszkowski \& Collins, 2016). Stoszkowski and Collins (2016), for instance, explain the social learning process of coaches and the possibility that a coaches' community of practice can change behaviour and professional standards.

As noted earlier, to consider a community as a community of practice, the three structural elements need to be present including a domain, practices, and a group of people who care (Wenger et al., 2002). The knowledge domain here is the broader field of Sport-for-All. Multiple issues can exist within the field and people from several sectors might share an interest in it without being a Sport-for-All expert (e.g., health experts interested in the health benefits of Sport-for-All). Regardless of their background, all Community of practice participants, distinguished by their shared interest in Sport-forAll, need relevant knowledge and/or competences. Wenger et al. (2002) defined practice as a "set of frameworks, ideas, tools, information, styles, language, and documents that community members share" (p. 29). The overall purpose of the practice is to create the basis for action, communications and problem solving, monitoring members' performance, and accountability for actions, but critical are the people and their knowledge sharing. Communities of practice can only exist when there is belongingness to it, whether or not people are conscious about their belonging. A feeling of accountability for and identification with the domain reflects this belongingness. Therefore, accountability and identification are good measures to identify the existence of a community of practice even when people do not recognize their participation in it.

Even in the presence of all three structural elements of communities of practice, knowledge sharing might not occur spontaneously or might be limited. Nonaka (1994) argued that knowledge is created through the conversion of different forms of knowledge. Knowledge is (re)created and implemented in new situations and contexts through processes of knowledge sharing and conversion. In communities of practice, the presence of a shared identity and knowledge domain allows social learning and the sharing and reshaping of practices so these practices can be used more widely (Kothari et al., 2015). Although the community of practice provides a suitable setting for knowledge sharing, knowledge brokers are required to help facilitate the process through analytical, technical and relational activities (Conklin, Lusk, Harris, \& Stolee, 
2013). They can, for instance, bring together communities of practice's knowledge producers and users from different disciplines.

Governing bodies of sport (e.g., Sport England) are taking up the role of knowledge brokers. They can connect researchers with practitioners to allow the application of scientific knowledge and innovations; are in the centre of a knowledge hub able to disseminate knowledge to practitioners in various organizations; and can provide the technical support, tools, or platforms for knowledge sharing (Girginov et al., 2015a). Governing bodies of sport have also knowledge depositories related to sport participation and practices developed by practitioners. Such dynamic knowledge inventories (e.g., databases, libraries, websites) can flexibly store up-to-date knowledge on practices as well as provide inventories of experts, organizations and practices structured so that knowledge can be accessed easily (Bastow, Dunleavy, \& Tinkler, 2014).

The relevance of communities of practice to Sport-for-All is significant. Sport organizations build on their human resources and knowledge in the communities of practices in which staff, volunteers, members, and athletes are involved. Organizations depend on communities of practice because they can be seen as constellations of interconnected competencies within them (Wenger, 1998). For instance, employees of governing bodies of sport can be members of a community of practice on sport infrastructure, elite, and school sport. These communities of practice connect and cross organizational boundaries. Knowledge, thus, resides in organizations and people (Lam, 1997), but also in and across these communities (Wenger, 1998).

Although all organizations involved in Sport-for-All can benefit from knowledge sharing, governing bodies of sport are dependent on the communities of practice. They can neither develop sport policy without experts' knowledge nor implement new practices without disseminating knowledge about the practice to those working in the field. Governing bodies of sport use appropriation (i.e., building up a new knowledge domain by transfer of knowledge from external sources) and probing (i.e., individuals and teams are given responsibility to build up a new knowledge domain from scratch) strategies to develop knowledge on promoting Sport-for-All (Girginov et al., 2015a). Hence, governing bodies of sport might not only be knowledge brokers but also deliberately cultivate the Sport-for-All community of practice to achieve objectives, such as increasing physical activity. Therefore, this research is not only concerned with identifying the existence of Sport-for-All communities of practice but also pays particular attention to the role of governing bodies of sport as knowledge brokers.

\section{Method}

We used a multiple-case study approach to examine the existence of Sport-for-All communities of practice and to identify the role of governing bodies as knowledge brokers in four cases at different levels. This approach was suitable because of the exploratory nature of the study of a complex phenomenon (Yin, 2017). The case study is a context-dependent approach to a social phenomenon and is premised upon the fundamental idea that "in the study of human affairs, there appears to exist only context-dependent knowledge" (Flyvbjerg, 2006, p. 211). The objectives were to learn new insights about Sport-for-All and how governing bodies of sport strongly involved in the communities of practice influence standards within the Sportfor-All communities of practice, and hence to challenge existing assumptions about Sport-for-All. We used an innovative and multiple set of data collection tools (Shaw \& Hoeber, 2016) to unravel how communities of practice can provide analytical generalisation.

We selected four settings: Sport and Development (global); Australia and England (National); and Flanders (regional). This range provided a variety of contexts, policies, and sport participation cultures. Girginov et al. (2015a) described the sport systems in Australia, Flanders, and England as consumption, education, and delivery oriented respectively. Sport and Development is a Swiss-based international organization, which several governmental and non-governmental agencies support, while the other three organizations were governmental entities. Sport and Development specializes in education, knowledge generation and sharing, and advocacy, and operated a global online platform: www.sportanddev.org/en. In all four cases, the organization offered several Sport-for-All programs targeting specific groups risking exclusion from sport and its benefits, but differences existed in the characteristics of the target groups. The case selection allowed studying the same phenomenon across four settings to seek patterns of similarities and differences in approaches towards Sport-for-All communities of practice.

Since communities of practice have no strict boundaries and are therefore difficult to delineate (Wenger, 1998), it was important to be clear in the study's delimitations. We did so by developing our study around the knowledge brokering role of governing bodies of sport, namely Sport Flanders (Flanders), Sport England (England), Australian Sports Commission (Australian Sport Commission, Australia), and Sportanddev (the International Platform for Sport and Development).

The Australian Sport Commission, Sport England, and Sport Flanders are governmental organizations shaping and implementing Sport-for-All policy based on systematic research and knowledge generation and dissemination. While these three organizations varied in size, budgets and remit, there was similarity in their objectives: Sport Flanders and Australian Sport Commission both had explicit knowledge sharing as one of their formal goals. Sportanddev is not a policy making or program implementing organization but an independent knowledge sharing institute. It operates globally but mainly virtually and is only focused on Sport and Development. The Sportanddev platform was established in 2003 as "a hub for sharing knowledge, building good practice, facilitating coordination and fostering partnerships between and within different stakeholders in Sport \& Development" (Sportanddev, 2016, "What is this platform for?," para. 1). Sportanddev evolved from a conference to the facilitator of a platform where people could meet virtually and share ideas (interview, 0112-2015). As an organization, Sportanddev is comparable with the Knowledge and Information Centre for Sport in Flanders 
and Sport England Insights Directorate. Both are departments of, and the information and knowledge centres for Sport Flanders and Sport England respectively, tasked to collect, share, and facilitate knowledge sharing on various strategies and programs for Sport-for-All.

\subsection{Data collection}

Considering the study's focus, data collection was centred on the facilitators of Sport-for-All within Sportanddev, Australian Sport Commission, Sport Flanders, and Sport England. To aim for reliability and content validity, we used triangulation in data collection by combining four sources of data: systematic analyses of websites; web monitoring data; interviews; and organisational documents. The analysis of secondary data, such as organisational documents, allowed an objective study of coded knowledge and initiatives of the governing bodies of sport to enhance the communities of practice. Primary data in the form of websites analyses and interviews provided subjective perspectives on how the Sport-for-All communities of practice were enhanced, offered insights in the relative importance of informal versus formal knowledge brokering activities, and served to confirm (or refute) findings from the document analyses. The authors who had insider knowledge in the Sport-for-All communities of practice in their own countries but not in each other's countries or regions followed established guidelines (e.g., Meyrick, 2006; Tracy, 2010) on qualitative data analyses to reduce bias, and increase transparency and systematic in data collection and analysis. Apart from triangulation, we used multiple coding and the use of an analytical framework to improve systematic analysis.

First, a systematic search was conducted by three researchers on the case organizations' websites (i.e., www.sportanddev. org, www.sportengland.org, www.sport.vlaanderen, www.bloso-kics.be, www.ausport.gov.au, and www.clearinghouseforsport.gov.au.) for the presence of Sport-for-All knowledge sharing, tools, and standards. These websites represented the main vehicle for cultivating communities of practice because of their cost-effectiveness. Both the Australian Sport Commission and Sport Flanders operated a separate website to their main website specifically for knowledge sharing purposes. These websites are the Clearinghouse for sport and Knowledge and Information Centre for Sport respectively and were also included in the analysis, resulting in the study of six websites. Sport Flanders revamped all websites in 2016 following a change in organisation branding. The Clearinghouse for Sport in Australia had existed as knowledge sharing entity of the Australian Sport Commission in its current form since 2012. Its platforms supported the transfer and development of knowledge on elite and grassroots sport. We performed the search over two week-long periods starting from February 13 , 2017 and March 13, 2017 respectively, to ensure that any changes on the sites were recorded. A similar approach was taken by Girginov et al.'s (2009) study of Canadian governing bodies of sport use of relationship marketing for promoting participation. We used a coding scheme based on the analytical tool developed by Wenger to systematically analyse the webpages and collect data from the websites of the knowledge brokers (Wenger \& Trayner, 2013). The tool included 66 indicators organised in 8 categories as follows: informing (17), networking (13), capacity building (8), community building (10), advocacy (6), problem solving (4), performance (4), and accountability (4).

Second, we monitored the web traffic on the four organizations' websites to identify the extent to which people used these knowledge repositories, and to compare this data with the interview data. We used the monitoring service www. similarweb.com for the period of mid-August until mid-October 2016. We collected data on average visits and their duration, bounce rate ${ }^{1}$ and average pages per visit, traffic by countries, and source. These indicators allowed capturing the level of engagement within the domain.

Third, we studied organizational structures of the Australian Sport Commission, Sport Flanders, and Sport England, and we identified key officials responsible for research and knowledge management. Sampling of those key officials for the interviews occurred through snowball sampling, with the authors using their personal contacts in the four case organizations to identify and contact the key people responsible for Sport-for-All in the four organisations. The sample consisted of a mix of policy officers responsible for knowledge sharing and department heads (e.g., head of the knowledge centre of the governing body of sport or head of the Sport-for-All promotion department). We conducted interviews with 3 individuals with Sportanddev, 5 with Sport Flanders, 2 with Australian Sport Commission, and 3 with Sport England. The purpose of the interviews was first to identify the specific groups of people (e.g., sport and development officers, community workers, youth leaders, volunteers) who comprised the communities of practice, and their interests. In addition, we sought to learn more on the knowledge sharing and creation process among these groups, viewed from the perspective of the knowledge brokers and how they perceived their roles in the Sport-for-All communities. We developed an interview guide including three main areas of organizational activities, including knowledge creation, transfer, and management supplemented by a range of questions. The interview format was semi-structured to allow the interviewer to expand on a point of interest as well as for informants to elaborate. Interviews had a varying duration between three quarters of an hour and two hours.

Fourth, we consulted relevant documents on the websites of Sport England, Sport Flanders and Australian Sport Commission that provided clues on knowledge sharing or sharing of practices related to Sport-for-All and added these as

\footnotetext{
${ }^{1}$ Bounce rate refers to the percentage of all people visiting a website that visited only one page of a website without browsing further on that website. High bounce rates are generally seen as negative because people are not searching for specific information further on the website.
} 
Table 1

Examples of actual knowledge generation and sharing activities.

\begin{tabular}{|c|c|c|c|c|}
\hline Activity & Sport England & Australian Sport Commission & Sport Flanders & SportandDev \\
\hline Informing & ++ & +++ & ++ & +++ \\
\hline Networking & ++ & +++ & +++ & +++ \\
\hline Capacity building & + & ++ & ++ & +++ \\
\hline Community building & + & ++ & + & ++ \\
\hline Advocacy & + & ++ & ++ & + \\
\hline Problem solving & + & +++ & / & ++ \\
\hline Performance & / & +++ & + & + \\
\hline Accountability & + & + & + & + \\
\hline
\end{tabular}

+++ Dominantly present.

++ Several examples.

+ Limited presence.

/ Not present.

Informing: member posts, comments, free tagging, integrated external feeds, advanced search capability, publications, project case studies and flash, selected bibliographies, categories and specified tags, reports, seeking stories, subscriptions on selected categories, archives organized by digital librarian, languages, newsletters, local correspondents, research databases.

Networking: profiles of people and organizations, project description, geomapping, people finder, following people and projects, job/volunteer postings, tweeting, requiring updates profiles, archiving, feedback on posts from G analytics, brokering connections, in-person visits, local and regional facilitators of connections.

Capacity building: self-assessment, toolkit, webinars and training on how to use it, focused courses (online, on-site, regional), organizational mentoring, workshops at global conferences, benchmarking different approaches to Sport-for-All across different contexts.

Community building: self-organized group practices, E-debate, regular debates, hot topic discussion, case studies, topical and regional groups, interactive visits and showcases, global practitioner conferences, regional gatherings, core groups.

Advocacy: open funding requests and offers, overview and history of the field, funding marketplace, strategic partnership, connecting to other fields, strategic conversations across stakeholder groups.

Problem solving: problem recognition and reporting, encouraging problem identification, problems solutions reporting, feasibility/needs/risks/impacts assessments.

Performance: self-reflections, KPI discussions, measure and evaluation tools, new performance measures development.

Accountability: boards' membership information, seeking board and committee members, annual reports, governance strategic development.

additional data to the analysis of website data. For Sportanddev, we analysed Wenger and Trayner's (2013) report premised on the community of practice lens on the working and knowledge enabling role of Sportanddev.

\section{Data analysis}

We coded the websites using the analytical framework of Wenger and Trayner (2013), according to which five actual and potential categories of knowledge activities existed: informing, networking, capacity building, community building, and advocacy (see the legend of Table 1 for explanation of each category). For this research, and following a discussion with Wenger and Trayner, we added three more categories: problem solving, performance, and accountability to better capture the brokering role of governing bodies of sport. First, based on analyses of the websites, the authors identified different target groups to which the webpages were oriented. Some pages, like the home page, were generic but other parts of the website were clearly intended for particular groups of visitors (e.g., coaches, parents, athletes, national governing bodies). We then coded the information found on the webpages for each of the different target groups using the analytical framework. For instance, the coding allowed us to see if there were community building tools for coaches and thus uncover segmentation in target groups within the Sport-for-All field. Second, we coded sub domains of knowledge, such as knowledge about sport participation, elite sport, sport infrastructure, programs, or sport policy. While the first coding started from the target group and the way these were approached. The second coding of the same website information included the content and the subdomains of knowledge that were present. The web monitoring provided coded descriptive data about the use of the websites in general. This did not allow us to see exactly which target group was using which knowledge. We analysed organisational documents by the subdomains and provided insights into standard Sport-for-All knowledge in these domains. In the Sportanddev case, these documents also showed how this platform evolved in its enabling role.

We transcribed and coded the interview data. Codes were related to the three elements of communities of practice, namely domain (including subdomains), practices, and people (belonging, identity, and accountability). Following Robson (2011), we developed a data coding and thematic analysis protocol to ensure consistency between the cases. Next, we coded the interview data deductively in NVIVO10. We used a constructionist perspective to analyse the interview data, which suggests that meaning and experience were socially produced and reproduced in specific socio-cultural contexts, rather than developed within individuals. Theme identification was both theoretical (i.e., deductive) or 'top down', and inductive (i.e., bottom-up) to capture emerging themes, and other aspects of the communities of practice. We conducted the analyses from the perspective of the role of governing bodies in the Sport-for-All communities of practice. For instance, when analysing the subdomains in the Sport-for-All communities of practice, the segmentation used by the governing bodies of sport provided information about the groups/individuals with whom a governing body of sport communicates, and who enhanced and coordinated learning. We identified these groups by studying the organizations' websites. 
Table 2

Target groups/ 'people' in the Sport-for-All community of practice.

\begin{tabular}{|c|c|c|c|c|}
\hline Target group & Sport England & Sport Flanders & Australian Sport Commission & Sportanddev" \\
\hline Coaches & $\mathrm{x}$ & $\mathrm{x}$ & $\mathrm{x}$ & \\
\hline Volunteers & $\mathrm{x}$ & & $\mathrm{x}$ & $\mathrm{x}$ \\
\hline Elite athletes & $\mathrm{x}$ & $\mathrm{x}$ & $\mathrm{x}$ & \\
\hline Parents & & $\mathrm{x}$ & $\mathrm{x}$ & $\mathrm{x}$ \\
\hline Schools (incl. physical education teachers) & $\mathrm{x}$ & $\mathrm{x}$ & $\mathrm{x}$ & $\mathrm{x}$ \\
\hline Board members & & & $\mathrm{x}$ & \\
\hline Local sport administrations & $\mathrm{x}$ & $\mathrm{x}$ & $\mathrm{x}$ & $\mathrm{x}$ \\
\hline Sport participants & $\mathrm{x}$ & $\mathrm{x}$ & $\mathrm{x}$ & $\mathrm{x}$ \\
\hline Governing bodies of sport & $\mathrm{x}$ & $\mathrm{x}$ & $\mathrm{x}$ & $\mathrm{x}$ \\
\hline Voluntary organizations & $\mathrm{x}$ & $\mathrm{x}$ & $\mathrm{x}$ & $\mathrm{x}$ \\
\hline Sport professionals & $\mathrm{x}$ & $\mathrm{x}$ & $\mathrm{x}$ & $\mathrm{x}$ \\
\hline Corporations & & $\mathrm{x}$ & $\mathrm{x}$ & $\mathrm{x}$ \\
\hline Women & $\mathrm{x}$ & & $\mathrm{x}$ & $\mathrm{x}$ \\
\hline Officials; referees & & & $\mathrm{x}$ & \\
\hline Policymakers & $\mathrm{x}$ & & $\mathrm{x}$ & $\mathrm{x}$ \\
\hline Sport scientists & $\mathrm{x}$ & $\mathrm{x}$ & $\mathrm{x}$ & $\mathrm{x}$ \\
\hline Dedicated major partner organizations & & & & $\mathrm{x}$ \\
\hline
\end{tabular}

* Sportanddev has no explicit target groups but those indicated here were inferred from the website analysis.

In sum, interview data gave insight into the formal and informal knowledge sharing processes in the communities of practice in which governing bodies of sport were involved. The websites revealed the enabling role of governing bodies of sport, knowledge domains and target groups, while the web monitoring quantified websites' frequency and purpose of use. We coded documents for presence of the subdomains and knowledge standards in Sport-for-All. Results from these different sources were then combined to analyse the existence of communities of practice by examining the three fundamental elements (domain, practice, community) and role of governing bodies of sport. This allowed us to meet the second research aim of this paper.

\section{Results}

\subsection{Knowledge domains}

Analysis of the websites delineated the relevant knowledge domains. Sport England's domains were mainly concerned with research and sport participation programs. Similar knowledge domains were present in the Australian Clearinghouse for Sport, while the Australian Sport Commission site displayed more news and knowledge on elite sport. The main Sport Flanders site provided practical knowledge and support on how to organize activities. All knowledge found on the websites was related to Sport-for-All or, in the case of Australia, also to elite sport, but there were no delineated sets of knowledge domains. This was different in Sportanddev where there are eight knowledge domains (i.e., disability, health, education, economic development, peace, child protection, disaster response, and gender).

\subsection{Practices}

Analysis of the websites' content revealed also differences in the practices shared by participants. In Sport Flanders, there was both knowledge, based on scientific research and more practical knowledge related to promoting Sport-for-All. In general, its two platforms tried to inform the Sport-for-All community on how to implement initiatives. Sport England went a step further by providing practical tools for monitoring participation among different groups and regions and through storytelling that illustrated Sport-for-All knowledge in context. However, apart from the Active Living tool (https:// activelives.sportengland.org/), the platform was not interactive, with only Sport England collecting, creating, and sharing knowledge. The Australian Sport Commission was the closest of the three governing bodies of sport to a knowledge creation and sharing platform because Sport-for-All stories could be posted by users, allowing a dynamic knowledge creation process to occur. Similarly, Sportanddev practitioners could post their experiences and knowledge on how to develop sport initiatives by writing a short clear note (i.e., as codified knowledge and stories). Although links to sites with practical tools existed, the information was rather brief, and visitors were directed to partner websites for more in-depth knowledge.

\subsection{Communities of people}

Website analyses provided further insights into the members of different communities. Information on Sport England's site was aimed at a range of target groups, especially women, and enabled networking. The other categories of knowledge activities on the website, except performance measurement (tools), were present but not prominent. For capacity building, for instance, there were several tool kits available, such as Value of Sport, Local Sport Profiles, or Small area estimate that 
Table 3

Governing bodies of sport web monitoring statistics.

\begin{tabular}{|c|c|c|c|c|c|c|}
\hline \multirow[t]{2}{*}{ Indicator } & \multirow{2}{*}{$\begin{array}{l}\text { England } \\
\text { Sport- } \\
\text { England }\end{array}$} & \multicolumn{2}{|l|}{ Flanders } & \multicolumn{2}{|l|}{ Australia } & \multirow{2}{*}{$\begin{array}{l}\text { Global } \\
\text { Sportanddev }\end{array}$} \\
\hline & & Sport-Flanders & $\begin{array}{l}\text { Knowledge and Information } \\
\text { Centre for Sport }\end{array}$ & $\begin{array}{l}\text { Australian Sport } \\
\text { Commission }\end{array}$ & Clearinghouse & \\
\hline visits (av) & 117000 & 45400 & 1400 & 131000 & 30500 & 79800 \\
\hline duration (av) & $1: 19$ & $2: 34$ & $2: 58$ & $5: 50$ & $1: 12$ & $2: 06$ \\
\hline $\begin{array}{l}\text { pages per visit } \\
\text { (av) }\end{array}$ & 2.07 & 4.76 & 1.86 & 8.31 & 1.49 & 2.3 \\
\hline bounce rate & $49.53 \%$ & $33,84 \%$ & $40,69 \%$ & $41,67 \%$ & $50,5 \%$ & $50,87 \%$ \\
\hline traffic by & $59.6 \%$ & $85.39 \%$ Belgium, $13 \%$ & $83.15 \%$ Belgium & $66.85 \%$ Australia & $48.82 \%$ & $12 \%$ U.S., $10 \%$ UK, 5,44\% Turkey; \\
\hline countries & UK & Netherland & & & $\begin{array}{l}\text { Australia; } \\
11 \% \text { U.S. }\end{array}$ & 4,6 Congo, $4 \%$ India \\
\hline $\begin{array}{l}\text { traffic source: } \\
\text { direct }(\%)\end{array}$ & 22.57 & 23.17 & 50.96 & 28.24 & 9.15 & 17.89 \\
\hline $\begin{array}{l}\text { traffic source: } \\
\text { referrals }(\%)\end{array}$ & 9.89 & 24.12 & 2.68 & 15.68 & 5.07 & 1.82 \\
\hline $\begin{array}{l}\text { traffic source: } \\
\text { search }(\%)\end{array}$ & 65.7 & 49.82 & 46.35 & 52.61 & 72.71 & 70.34 \\
\hline $\begin{array}{l}\text { traffic source: } \\
\text { social }(\%)\end{array}$ & 1.63 & 0.72 & 0 & 1.62 & 0 & 4.28 \\
\hline $\begin{array}{l}\text { traffic source: } \\
\text { mail }(\%)\end{array}$ & 0.2 & 2.16 & 0 & 1.84 & 13.07 & 5.67 \\
\hline
\end{tabular}

were not particularly oriented to a target group. Networking was enhanced through the website but closely monitored by Sport England. Partners wishing to share their projects did so but only after approval from the administrator. More direct interaction was limited to Facebook and Twitter. This was very similar to Sport Flanders, which invested heavily in informing different target groups, and in developing search engines and databases.

The search engines and databases allowed for networking but the websites did not facilitate direct interaction among partners and practitioners. Sport Flanders also invested in community capacity building and taught partners how to deliver Sport-for-All. The website was replete with standards and knowledge on how schools, sport clubs, and other entities could contribute to the Sport-for-All aim. However, problem solving was not a dimension that was clearly present and others, such as community building, were less well-developed. Both Australian Sport Commission's websites provided a more interactive platform to support the Sport-for-All communities of practice. There was a large amount of information, standards, online courses, and databases for all target groups. While the Australian Sport Commission had a more developed and complex website, according to the dimensions suggested by Wenger and Trayner (2013), it too had limitations in the area of community building. For instance, open e-debates among practitioners and discussions through the Australian Sport Commission websites were scarce. In contrast, the Sportanddev's platform intended to facilitate discussion, interaction, and sharing of best practices rather than purely informing. However, our results showed that although the tools were present on the Sportanddev platform, those were not intensively used. Additionally, Sportanddev was organized differently to the other three case sites. It was structured around knowledge domains, which facilitated sharing the practices of each of the domains among groups of people with similar functions. Table 1 displays a summary of the website analysis.

We list the websites' target groups as identified on the webpages in Table 2. Despite apparent similarities across cases' target groups, there were also differences. For instance, women were an explicit target group for the Australian Sport Commission and for Sport England, while not explicitly recognized on Sport Flanders' platforms. Other target groups included volunteers, parents, referees, and corporations. An interesting difference between the three governing bodies of sport websites and Sportanddev was that the latter implicitly set boundaries around a practice, while the formers' boundaries were designed around people/target groups, such as volunteers or parents.

Although there were gradations in the functionality of the platforms, the three governing bodies of sport sites proved useful. An indirect but objective way to assess this was with traffic metrics on the four websites. Table 3 provides some wellestablished web monitoring metrics. Sport England's site was used far less than those of Sport Flanders or the Australian Sport Commission, and time spent on it was shorter. Sportanddev, despite its worldwide orientation, was also not visited frequently in relative terms. Although there were no standards on how long a visit should take to allow for knowledge sharing or absorption, the stories and tools needed time to be accessed. This may be problematic given that the average visit durations at the Sportandev site was only two minutes. The Australian Sport Commission was the most visited, with the longest duration and most pages accessed.

The country of origin of visitors also differed for each of the sites. Surprisingly, for Sport England only 60 percent of the visits were from the UK. For the Flanders sport's sites, visits from Belgium were around 85 percent, with another 10 percent coming from Dutch users. The Australian Sport Commission and the Clearinghouse sites had 67 and 49 percent home visitors respectively. Sportanddev's traffic by countries indicated large shares from the US (12\%), the UK (10\%), Turkey (5\%), Congo $(5 \%)$, India (4\%), and more than $60 \%$ further spread around the world.

Traffic source was examined to Australian Sport Commissionertain whether it was comprised of a particular group of people who knew and recognized the organizations as knowledge brokers, and who accessed the sites directly when they 
wanted to learn or share knowledge. Direct access to the sites was indicative of this. Other possibilities to access a site were through search engines (e.g., Google), via referrals on other sites, links in e-mails or social media (e.g., in a tweet). Visitors to the Sportanddev platform mainly accessed the site via a search engine. This was also the case for the Clearinghouse in Australia. For the sites in Flanders, access via search engines was equally common but many visitors came directly to them. This metric provided a rough indication of the level of visitors' knowledge about the information needed and where to find it directly. For those accessing via search engines the keywords entered for the analyzed period were as follows: Sport England: Sport England, community sport, list of sports; Australian Sport Commission: Australian Sport Institute, AIS, Australian Sports Commission, Australian Institute of Sport; Sport Flanders: Bloso (former name of Sport Flanders), mountain bike route, basic fit, multimove; and Sportanddev: physical activity, impacts of sport, nature news, positive effects of sport. Surprisingly, there were no keywords related to development of any of the specific knowledge domains of the Sportanddev sites. In general, the keywords were very vague and did not indicate any specific search. However, a limitation of this metric was that the keyword information provided by the web monitoring services was limited and may vary over time.

\subsection{Knowledge brokers}

Interview data with experts in each of the studied organizations provided further information on the knowledge brokering roles and existence of Sport-for-All communities of practice. In Sportanddev, the community of practice consisted of experts who had some links with sport and development and "who all bring their own little package of expertise to the group and some come from the practitioners' side, some from the academic side, some are policymakers" (interview, 01-122015). Sportanddev maintained a list of individual and organizational members, but it was by no means exhaustive of all people involved in sport and development. Interviews indicated that hardly any of those members could be considered sport and development experts, in so far as this was a unique field of expertise with a strong interdisciplinary nature bound by a concern for sport in the world of development.

They [people active on the Sportanddev platform] share, they publish reports, there is obviously a sort of a stance of 'sport and dev', there is a way they view sport in the world of development. You know it's people who identify with that stance and who feel accountable for the stance and within their own country they may be the only person who does. But they've got in the back of their minds that there is this international entity out there where they belong, where they are not just a little voice in the wilderness. (interview, 08-11-2015)

Although Sportanddev was a growing community at a rate of 40 percent increase in membership each year (interview, 01 12-2015), it maintained a large and stable core group of more than 500 experts. Conferences where people could meet in person were important complements to the virtual knowledge sharing processes. However, although practitioners, scholars and experts used the platform because of their common concern for sport in the world of development, they might not have seen it as a community to which they belong.

The importance of Sportanddev's facilitating role manifested in knowledge sharing promoted through the e-platform. Given the value of this virtual platform, actual activities, software tools, and real sharing of practices were required to maintain sufficient traffic and to allow this facilitating role. The latter sometimes needed to be facilitated by language editing (interview, 01-12-2015). In Sportanddev, sharing often required making knowledge explicit in a written or visual form so it could be used. This forces practitioners, policymakers, and researchers to reflect on the knowledge they possessed and applied it in their daily practices. It took more than five years before some sort of common understanding among the members on the benefits of the Sportanddev community developed. Until then there was no clear set of shared values in this community of practice, but rather a common understanding of sport as a universal tool for communication and a source of positive notions (interview, 01-12-2015).

The brokering roles of governing bodies of sport in Australia, England, and Flanders were much more local, with more personal contacts and content connected to the specific Sport-for-All policies in each of the constituencies, such as a focus on activating women in sport in England. There were clear similarities among the roles of Australian Sport Commission, Sport England, and Sport Flanders. Governing bodies of sport's interviewees were explicit in their depictions of the communities of practice. For example, an Australian interviewee commented:

The whole theory behind the Clearinghouse is you create this place and it's really basic. You create a place, a go to place, with all this explicit knowledge and it's supported by a good client . . Clearinghouse for Sport, as a means to bring together key stakeholders in the sport knowledge community and build a coalition for sharing knowledge, with the Australian Sport Commission research being only one aspect to the broader array of knowledge shared . . People who are actually delivering it know it's much more. It's a strategy. It's around changing behaviour. It's around joining up. (interview, 21 July, 2014).

In the same vein, Sport England's knowledge manager expressed that "Mutuality is at the heart of it - Sport England helps them (various delivery partners, explanation added) understand issues and they help Sport England understand practical challenges facing these partners" and that "Sport England works in partnership with the sector, we do not impose ideas on the sector" (interview, 22 July 2014).

Sport Flanders Sport-for-All knowledge management system was labelled as educating and this role was also strongly manifest in the Flemish Sport-for-All community of practice (Girginov et al., 2015a). At the time of data collection, 
knowledge was dispersed among a large number of individuals and organizations, and Sport Flanders was both spreading and using the knowledge of others. Previously, Sport Flanders used to educate other organizations about the importance of Sport-for-All. Sport Flanders took a strong facilitating role in the community of practice. "We seek knowledge purposefully, for instance we have a project group and platform on Sport-for-All and there we collected our knowledge" (interview, June 24, 2014). Another interviewee emphasized Sport Flanders' role in spreading good practices and even standards for Sportfor-All initiatives:

We place best practices on our website, so others can see and do what they like with it. You can see this as sharing knowledge. We have an opinion on which method works best and we have specific examples of it, these are placed on the website as good practices. We also suggest doing things, like sport for seniors, and we suggest how you can organize such things on a local level (interview, June 10th, 2014).

Sport Flanders collaborated extensively. "A lot is being done in collaboration with partners, so we exchange automatically knowledge. It is a function of our activities but not as structured as we intend to do in the future" (interview, June 3, 2014). There was a need to balance between formally managing the communities of practice and allowing freedom and informal interactions. One sport participation expert mentioned:

"Sharing knowledge is informal, there is no systematic approach like now we are going to write to all local sport administrations. Yes, we inform through our website and maybe that is considered formal, but I see it as informal because they are not obliged to use the knowledge on the website, we just make suggestions" (interview, June 10 ${ }^{\text {th }}, 2014$ ).

Several of the initiatives in Flanders were related to knowledge storing (e.g., the Knowledge and Information Centre for Sport database and the Sport database with club and infrastructure data) but the campaign "Sports people enjoy more" that started in 2016 and lasted for several years more actively invited interaction and sharing of practices.

\section{Discussion}

\subsection{Sport-for-all as a community of practice}

We empirically examined the existence and functionality of four Sport-for-All communities of practice and to uncover the broker role of governing bodies in them. The analysis showed that in each of the four cases the organizations' websites stored an extensive range of readily available information and knowledge. Interview data confirmed that sport participation in the three countries represented a highly fragmented rich knowledge domain. These domain characteristics were also present in sport and development. Hence, the results suggested that Sport-for-All was a knowledge-intensive, and even researchdriven sector, in addition to its obvious practical focus.

In a knowledge-driven sector, there is a need for knowledge sharing, so it can be spread throughout the community, and communities of practice are vehicles that enable that (Wenger, et al., 2002). Our results revealed the presence of the three structural communities of practice prerequisites (i.e., domain, practices, community) in each of the case organizations. The responsibility for making sport accessible to all seemed to have been sufficient as a common denominator allowing a vastly culturally diverse group of people to navigate all four cases' platforms. Despite differences in terminology, languages and backgrounds, there was an underlying concern for sharing Sport-for-All knowledge. This meant that best practices, information, and knowledge on specific Sport-for-All initiatives could be transferred across contexts, as long as members of the communities of practice had a shared understanding of the challenges, objectives and the evidence to support it. For instance, it was clear that members seem to understand the importance of lifelong sport participation for mental and physical health as well as the fact that socio-economic status influences sport participation. The experts interviewed confirmed the existence of such shared understanding and considered this as a key element in the survival of the Sport-forAll communities of practice.

Further, the high interest in the domain, combined with the practices and the interactions within the community, stimulated communities of practice's members to be at the cutting edge of their domain. Latest insights and new methods for reaching out disadvantaged communities needed to be spread among members who were eager to learn and develop their knowledge further. Crucial for this learning process and the creation of these communities has been the spread of modern technology and the Internet in particular (Stoszkowski \& Collins, 2016). Both Australian Sport Commission and Sport England boast dedicated extensive online platforms that allowed for sharing and developing practice in a collegial way. According to the interviewees, practitioners were interested in receiving new knowledge and working with it.

People are key in the communities of practice where experts and practitioners have knowledge embodied (experiencebased) or embrained (cognitive) and can apply it in practice (Lam, 1997). Thus, knowledge resides among the people who can use it or develop it further. The sites were clearly oriented to make their members more knowledgeable. The Sport-for-All communities of practice in the cases studied had no clear boundaries but, at their core, were groups of organizations and people (e.g., in Flanders employees of Sport Flanders, Flemish Sport Federation, and the Institute for local Sport and Recreation Policy; in England local authorities and national governing bodies' members working in sport development). However, there were also plenty of activities and sharing with other sport and non-sport organizations and individuals involved in Sport-for-All. Hence, much sharing had been taking place at the borders of the community. 
Wenger (2000) emphasised the importance of activity at the boundaries of the communities of practice because it is there where people connect with each other and knowledge domains are combined, resulting in the creation of new knowledge. Knowledge sharing and creation within the core of the community and at the communities of practice's boundaries perform two different and mutually enhancing functions. The first function is diffusion of knowledge among members involving knowledge creation through socialization, and the second allows new knowledge to flow into the community. Thus, communities of practice should not be too closed because their knowledge creation process will be diluted. Learning processes at the core and at the boundaries of communities of practice need to be balanced allowing both sufficient social learning among the core members to sustain the common interest and access to new knowledge (Wenger, 2000).

Analysis revealed the existence of Sport-for-All communities of practice in each of the four different cases because elements of communities of practice were clearly present and although data did not allow insights into the specific interactions in this community, it highlighted governing bodies' knowledge brokering role.

\section{Cultivating the sport-for-all community of practice}

Based on the interviews and websites analysis, two conclusions emerged: (a) the partners and client base of the three governing bodies of sport and Sportanddev included a range of public, commercial, and non-for-profit agencies as wellas numerous sport participants; and (b) governing bodies of sport had developed their Sport-for-All communities of practice coordinating role over the years. In Belgium, for instance, a network of people at sport federations, clubs, local sport administrations, educators, infrastructure managers, and others were all connected to both Sport Flanders and in the Sportfor-All community of practice, because of their engagement and alignment with its cause. Although those partners had been collaborating for years, as mentioned by the interviewees, a community of practice facilitated by a knowledge broker seemed to allow a more effective knowledge sharing and creation process that was very helpful in implementing Sport-for-All policies, as evidenced by governing bodies of sport's attempts to facilitate a community of practice in Sport-for-All.

Content on the websites studied showed how governing bodies of sport value the Sport-for-All field in terms of priorities, target groups, and knowledge considered worth disseminating. Clearly, all four organizations used the virtual platform for knowledge sharing purposes and not just to showcase what they did. This was most prominent in Flanders and Australia with dedicated platforms (i.e., Knowledge and Information Centre for Sport and the Clearinghouse for Sport) separated from the organization's main site. But, in all cases, knowledge was collected and made accessible to a range of target groups. Although websites did not provide the full picture of initiatives, they were indicative of how governing bodies of sport saw their role. Furthermore, people preferred searching online when they had questions and considered these platforms as their major information source instead of direct contacts with experts. This is similar to the case for health care where people resort to the Internet for health advice (Nath, Huh, Adupa, \& Jonnalagadda, 2016). Publishing knowledge through governing bodies of sport websites, combined with practitioners' common practice of consulting online sources, stimulates knowledge sharing and creation. Hence, decisions concerning the Sport-for-All content to publish online directly influence the communities of practice.

Interview data indicated that the organizational cultures of Australian Sport Commission, Sport Flanders and Sport England had been broadly supportive of the process of knowledge creation and in nurturing the communities of practice. Management encouraged staff in the three organizations to systematically enhance their general and area-specific knowledge through a variety of formal and informal forums. The existence of a team structure, which was formed typically around specific projects and knowledge domains, supported this process (interview, June 3, 2014).

It is important that not only the staff of the governing bodies of sport need to feel a sense of belonging to the communities of practice, but other practitioners as well. Governing bodies of sport have been trying to enhance the three types of belonging in the context of communities of practice suggested by Wenger (2000), viz., engagement, imagination and alignment. Identifying target groups uncovered which practitioners were considered part of the community of practice according to the governing bodies of sport. Although websites were accessible to everyone, by delineating specific knowledge domains (e.g., Sportanddev) or target groups (e.g., Sport Flanders), implicit boundaries were set. As a consequence, people not belonging to the target group might not consider the information relevant for them and thus might not consult or interact with the site. In this way, knowledge and people are grouped. Furthermore, people who belong to established target groups and receive hands-on knowledge might feel more accountable for how they use it in their own daily practices. Sportanddev organized its website around knowledge domains instead of target groups and created (sub) communities around particular topics. Regardless of one's function, background, position, job or role, anyone interested, concerned, and feeling attachment to the topic could participate in the online community and experience a sense of belonging to it. This facilitated interactions across people's roles. While a target group-oriented website was used by the other governing bodies of sport, as a convenient tool for informing people, it was less preferable from a communities of practice perspective. A target group-oriented website might discourage interaction among coaches, parents, athletes, and officials interested in a specific practice because they are placed in different (sub) communities. Communities of practice develop around a common concern crossing boundaries, while target group-based websites might enforce existing boundaries between organizations, roles, and hierarchies.

Imagination to create a sense of belonging is reflected in the community building efforts and identity creation (Wenger et al., 2002). For example, the "be inspired" messages throughout Sport England's platform provided identity to the community members. The Sport Flanders sites used the slogan "sports people experience more" to create the feeling of a 
community of people who play sport, have fun, are excited to be a member of that community, and to contribute to it. The Australian Sport Commission's site promotes examples of elite sporting success but seems less concerned with creating a Sport-for-All identity.

Since this study used mainly the official website of the four organizations to analyze the process of cultivating communities of practice, it is important to recognize that these sites were not just a computational infrastructure that supported the design and use of certain applications. Governing bodies' websites, as the full name of Sportanddev made explicit, represent a platform. Platforms perform an important discursive function, which, in the case of sport, sanctions a specific understanding of participation, and its value to individuals and society. As Gillespie (2010), p. 351) observed, "the 'platform' is defined not just by height, but also by its level of surface and its openness to those hoping to stand upon it." The inclusiveness of Sport-for-All platforms therefore, becomes one of their defining features. Platforms also need to address tensions and discrepancies between user-generated versus organization-produced content, as well as between cultivating a community of practice and serving political agendas.

The communities of practice have an identity created through numerous artifacts and interactions (Wenger, 1998). These identities are at the heart of what interests the members and exist over time, even when members join or leave the community. Alignment, as the third form of communities of practice belonging, is reflected in the website tools designed to support advocacy. These are, however, limited in all four cases because few initiatives or tools reflect strategic partnerships or strategic conversations. Hence, although there were well-developed websites serving Sport-for-All communities of practice, their potential was underexploited. This finding echoes Wenger and Trayner's (2013) strategic review of Sportandev, such that members' engagement is critical for the cultivation of communities of practice. People did not utilize key functionalities supported by web technology that allow more community building (e.g., E-debate, Wordpress, Drupal), including advocacy and networking. Those technologies allow to create blogs or web space where people can contribute and jointly create content and knowledge.

Capacity and community building, and advocacy represent strategic activities that go beyond the effort of managing a website and are premised on engaging members and other players in the Sport-for-All field. Governing bodies of sport were not capitalizing on the opportunity to create a full virtual platform to support the Sport-for-All communities, and thus to enhance the commitment of its members. This conclusion is in line with Polanyi (1962) observation that commitment underlies human knowledge creating activities and that individual commitment is predicated on three key factors: intention (i.e., the exercise of consciousness), autonomy (i.e., the ability to express one's own personality and intentions) and fluctuation (i.e., continuous interaction with the external world).

The Sport-for-All knowledge brokers can play a role in solving problems that are of major concerns for the communities of practice, such as how to engage disadvantaged groups in sport. There was limited evidence on the websites examined illustrating that problem solving was of great importance to the case organizations. The same goes for evaluating the performance of a specific community, as only governing bodies of sport's annual reports were available. This style of informing the community and the limited interactive use of the sites limited the possibility of creating a sense of belonging to a community of practice. From an interaction perspective, more important are the tools used for networking and capacity building that create engagement within the community. For instance, capacity building efforts can result in establishing applied standards and practices. Directing these standards towards specific target groups makes the groups more prone to consider their use in practice.

\section{Pitfalls in the sport-for-all communities of practice}

Applying the concept of community of practice as a lens for studying the knowledge brokering role of governing bodies of sport, coupled with awareness of the critics questioning the management focus on the concept (Li et al., 2009), allowed identification of some areas of improvement in the four cases. Communities of practice need boundary spanners and facilitators (Wenger, 2000), a role clearly taken by the governing bodies of sport. Both interview insights and website data highlighted the management perspective on the Sport-for-All communities of practice because of the governing bodies of sport taking a strong role in cultivating these communities (Wenger et al., 2002) to the extent that their self-organizing character might be questioned. The platforms of the governing bodies of sport tended to offer knowledge in the form of standard practices with limited interaction instead of standards emerging through interaction of the practitioners. In contrast, the Sportanddev staff did not really manage the Sportanddev community; rather, social learning was facilitated within it. The important point, as Wenger et al. (2002), p. 9) observed, is that "Communities of practice do not reduce knowledge to an object. They make it an integral part of their activities and interactions, and they serve as a living repository for that knowledge." Members of communities of practice benefit their organizations through knowledge created and shared in the community and from the new ideas that are brought into the organization. For organizations premised on knowledge, such as governing bodies of sport, this is essential for their long-term existence (Girginov et al., 2015a). However, governing bodies of sport need to facilitate sharing among the partners instead of hoarding knowledge at their organization, and selectively pushing it into the community. For instance, Sport Flanders was often too dominant and controlling in the facilitating role because, instead of facilitating interactions and having knowledge shared through interactions among the people in the community, Sport Flanders felt the need to collect all knowledge and then push knowledge towards other partners while keeping control on the knowledge flows. Also, existing webpages and e-tools heavily emphasized storing and diffusing knowledge instead of creating knowledge by interactions in the domain. Because of this particular role taken by 
governing bodies of sport, they were neither actively enhancing learning in the communities of practice nor learning themselves as actors in this community.

Thus, governing bodies' role posed a threat to the communities of practice because it led to a number of risks. First, group thinking might occur on the level of governing bodies of sport's knowledge brokers (Roberts, 2006), resulting in the dominance of less than optimal practices, e.g., the idea that organizing a mass recreational sporting event automatically increases the number of sportspeople in a community. Second, limiting interactions and knowledge sharing might occur when partners feel that governing bodies of sport are collecting knowledge and deciding on the standards in the community without consultation. Third, if the knowledge broker is not considered to be legitimate, other brokers in the community might emerge. Fourth, data revealed that to some extent, the studied communities of practice showed characteristics of communityship (Mintzberg, 2009), where the strong policy implementation focus of the brokers blurred their knowledge brokering role and mixed it with the hierarchical role of governing bodies of sport. This pitfall might be a barrier to change in the communities of practice because disruptive innovations might be difficult given the current dominance of brokers and boundary spanners in Sport England and Sport Flanders. These pitfalls impact on the implementation of Sport-for-All initiatives. However, they also seem to be consistent with an inherent dilemma faced by boundary spanners, who are defined by their ability to engage with others and deploy effective relational and interpersonal competencies (Williams, 2002). As Williams (2002), p. 111) suggests, this is not unproblematic because boundary spanners develop skills allowing a balance between breaking down boundaries and at a same time enforcing boundaries to protect from engaging with others' problems' or "a balancing act between inclusion and separation, dependence and autonomy".

Furthermore, the practice of sport participation is a set of frameworks, ideas, tools, language, stories, and documents that community members share. The notion of practice denotes a set of socially defined ways of workings and goes beyond the tangibles, such as a Website or a report, and implies interactions and developing a set of behaviors and common standards. It was clear that the websites are supporting the communities of practice, but that personal interactions and knowledge exchange are more crucial. The analysis of web monitoring results, which demonstrated many visits but equally large bounce rates and limited direct visits, supported this conclusion. Hence, in three cases, the websites were only supporting the communities of practice, while in the fourth (Sportanddev), the platform was at the core of the communities of practice. However, even in the Sportanddev case, conferences were compulsory to allow personal contacts. Applying Wenger and Trayner's model (2013) revealed that the governing bodies of sport websites of Australia, England, and Flanders included more incremental functionalities (such as informing and networking) to support the communities of practice and less strategic ones (such as advocacy). On the Sportanddev site there was more attention to strategic aspects, such as community building, but there was potential to further increase these functionalities and intensify their use.

Communities of practice easily cross boundaries of sport organizations, and even inter-sectoral boundaries are no hurdle for the communities of practice. Ultimately, communities of practice should allow for a change of the whole Sport-for-All approach because they are able to facilitate systems changes (Harris \& Jones, 2010). We did not observe such large changes in any of the cases studied. The communities of practice were not using their full potential, for instance, these did not drive a system's change in Sport-for-All, while such change might be needed. One example here is that organized sport participation increased in most European countries and Australia until a decade ago but since has only grown marginally or even flattened, seemingly having reached a maximum within the current sport system and policies (Eime et al., 2015; Hoekman, Breedveld, \& Scheerder, 2011). The communities of practice lens suggests that Sport-for-All learning and sharing is limited because of the lack of possibilities for all practitioners to contribute to the community. A more fully active community might be necessary for change (Goodyear, Casey, \& Kirk, 2014).

Sport-for-All is facing challenges, as Wenger and Trayner's (2013) study of Sportanddev, as a sport delivery community, concluded that the communities of practice was not exploited to its full extent and that what was required was more sense of belonging to the community and more sharing among the practitioners in the communities. We found that English and Flemish governing bodies websites worked on the identity and belonging aspects, while Sportanddev and Australian Sport Commission scored better on the sharing part but none of the four resembled a fully-fledged community of practice, thus limiting the opportunities for improving Sport-for-All in their regions.

\section{Conclusion}

Sport-for-All requires social learning processes and the community of practice provides a platform for this learning. Although the concept of community of practice in its narrow sense might not fully match the instrumental approach taken in this study, its broader applicability proved a useful lens for studying the extent to which knowledge is shared and created in the whole community of people and actors involved in Sport-for-All as well as unravelling the role of the knowledge brokers within it. The four cases demonstrated that Sport-for-All communities of practice are active and play an important role in shaping practices in the field but fall short of exploiting their full potential. We noticed some limitations and pitfalls. On the one hand, communities of practice need brokers and boundary spanners, but, on the other hand, dominance of those brokers might be affecting the working of communities. A well-working social learning process in communities of practices is crucial to advance knowledge about enhancing sport participation.

A community of practice lens allows understanding the challenges of delivering Sport-for-All, for instance on how to develop knowledge to increase sport participation among certain target groups or enhance social learning so all people involved in Sport-for-All have the best available knowledge. The contribution to sport management lies in applying the 
community of practice lens to Sport-for-All practices. The value of communities of practice in sport management extends beyond Sport-for-All communities of practice and has applicability to offer to other knowledge-intensive areas of sport, such as elite sport, governance, coaching, and fan monitoring. The concept of community of practice adds to the sport management literature on collaboration by investigating more organic collaborations in which not common goals or activities, but common interests and knowledge, are central. We show the importance of knowledge sharing and the role of governing bodies of sport in such types of informal collaborations. It also underlines that implementing sport policy builds on knowledge that is developed and shared in a larger community involving all kind of experts and brokering organizations. Policymakers working on the implementation of Sport-for-All objectives should be aware of the potential of well-cultivated but not broker-dominated communities of practice. Finally, we add to understanding the governance of governing bodies of sport by indicating an inherited dualism between their enhancing and inhibiting role in knowledge sharing and creation, which has implications for the realization of the sport-for-all policy and governance of governing bodies of sport. Governing bodies of sport managers need to be aware of this dualism and use brokering the communities of practice as an explicit part of their task in a facilitating rather than controlling way.

An important limitation of our study concerns the data that were collected through publicly available sources, such as websites, and interviews with community of practice knowledge brokers, instead of with members of the Sport-for-All communities of practice. Further research could include interviews with more actors, especially those on the borders of the communities of practice, and in other connected communities.

Future scholars can also analyze more in-depth the individual and organizational social learning processes within the community and take a longitudinal approach to understanding how practices are learned and become standards. The study is limited in scope with the focus on the knowledge brokering role of governing bodies of sport, which is an important influence on the social learning in the communities of practice but is not about unravelling the learningprocess itself.

\section{References}

Ardichvili, A. (2008). Learning and knowledge sharing in virtual communities of practice: Motivators, barriers, and enablers. Advances in Developing Human Resources, 10(4), 541-554.

Aubry, M., Müller, R., \& Glückler, J. (2011). Exploring PMOs through community of practice theory. Project Management Journal, 42(5), 42-56.

Ayas, K., \& Zeniuk, N. (2001). Project-based learning: Building communities of reflective practitioners. Management Learning, 32(1), 61-76.

Barley, S. R., \& Kunda, G. (2001). Bringing work back in. Organization Science, 12(1), 76-95.

Bastow, S., Dunleavy, P., \& Tinkler, J. (2014). The impact of the social sciences. London: Sage.

Bergsgard, N. A., Houlihan, B., Mangset, P., Nodland, S. I., \& Rommetvedt, H. (2007). Sport policy: A comparative analysis of stability and change. Routledge.

Brown, J. S., \& Duguid, P. (1991). Organizational learning and communities-of-practice: Towards a unified view of working, learning and innovation. Organization Science, 2, 40-57.

Coalter, F. (2013). Sport for development: What game are we playing? London: Routledge.

Conklin, J., Lusk, E., Harris, M., \& Stolee, P. (2013). Knowledge brokers in a knowledge network: The case of Seniors Health Research Transfer Network knowledge brokers. Implement Science, 8(7), 1-10.

Cousens, L., \& Barnes, M. (2009). Sport delivery in a highly socialized environment: A case study of embeddedness. Journal of Sport Management, 23(5), 574590 .

Cousens, L., Barnes, M., \& MacLean, J. (2012). Strategies to increase sport participation in Canada: The role of a coordinated network. International Journal of Sport Management and Marketing, 12(3/4), 198-2016.

Culver, D., \& Trudel, P. (2008). Clarifying the concept of communities of practice in sport. International Journal of Sports Science \& Coaching, 3(1), 1-10.

Dobbels, L., Voets, J., Marlier, M., De Waegeneer, E., \& Willem, A. (2018). Why network structure and coordination matter: A social network analysis of sport for disadvantaged people. International Review for the Sociology of Sport, 53(3), 572-593.

Edwards, M. B. (2015). The role of sport in community capacity building: An examination of sport for development research and practice. Sport Management Review, 18(1), 6-19.

Eime, R. M., Sawyer, N., Harvey, J. T., Casey, M. M., Westerbeek, H., \& Payne, W. R. (2015). Integrating public health and sport management: Sport participation trends 2001-2010. Sport Management Review, 18(2), 207-217.

Flyvbjerg, B. (2006). Five misunderstandings about case-study research. Qualitative Inquiry, 12(2), $219-245$.

Garner, P., \& Hill, D. M. (2017). Cultivating a community of practice to enable coach development in Alpine ski coaches. International Sport Coaching Journal, 4 (1), 63-75.

Gillespie, T. (2010). The politics of' platforms'. New Media \& Society, 12(3), 347-364.

Girginov, V. (2008). Management of sport development. Oxford: Elsevier.

Girginov, V., \& Hills, L. (2008). A sustainable sports legacy: Creating a link between the London Olympics and sports participation. The International Journal of the History of Sport, 25(14), 2091-2116.

Girginov, V., Taks, M., Boucher, B., \& Holman, M. (2009). Canadian national sport organisations' use of the web for relationship marketing in promoting sport participation. International Journal of Sports Communication, 2(2), 164-184.

Girginov, V., Toohey, K., \& Willem, A. (2015a). Creating and leveraging knowledge to promote sport participation: The role of public governing bodies of sport. European Sport Management Quarterly, 15(5), 555-578.

Girginov, V., Toohey, K., \& Willem, A. (2015b). Information, knowledge creation and innovation management in sport: An introduction to the thematic section. European Sport Management Quarterly, 15(5), 516-517.

Goodyear, V. A., Casey, A., \& Kirk, D. (2014). Tweet me, message me, like me: Using social media to facilitate pedagogical change within an emerging community of practice. Sport, Education and Society, 19(7), 927-943.

Green, M. (2006). From 'sport for all'to not about 'sport'at all?: Interrogating sport policy interventions in the United Kingdom. European Sport Management Quarterly, 6(3), 217-238.

Grix, J., \& Phillpots, L. (2011). Revisiting the 'governance narrative':'asymmetrical network governance'and the deviant case of the sports policy sector. Public Policy and Administration, 26(1), 3-19.

Harris, A., \& Jones, M. (2010). Professional learning communities and system improvement. Improving Schools, 13(2), $172-181$. 
Hoekman, R., Breedveld, K., \& Scheerder, J. (2011). Introduction to the special issue on sports participation in Europe. European Journal for Sport and Society, 8 $(1-2), 7-13$.

Houlihan, B. (2008). Public sector sport policy developing a framework for analysis. International Review for the Sociology of Sport, 4O(2), $163-185$.

Houlihan, B., \& Green, M. (2009). Modernization and sport: The reform of Sport England and UK Sport. Public administration, 87(3), 678-698.

Hylton, K., \& Totten, M. (2008). Community sports development. In K. Hylton, \& P. Bramham (Eds.), Sports development: Policy, process and practice (pp. 77117). London: Routledge.

Kirkman, B. L., Cordery, J. L., Mathieu, J., Rosen, B., \& Kukenberger, M. (2013). Global organizational communities of practice: The effects of nationality diversity, psychological safety, and media richness on community performance. Human Relations, 66(3), 333-362.

Kothari, A., Boyko, J. A., Conklin, J., Stolee, P., \& Sibbald, S. L. (2015). Communities of practice for supporting health systems change: A missed opportunity. Health Research Policy and Systems, 13(1), 33.

Lam, A. (1997). Embedded firms, embedded knowledge: Problems of collaboration and knowledge transfer in global cooperative ventures. Organization Studies, 18(6), 973-996.

Lave, J., \& Wenger, E. (1991). Situated learning: Legitimate peripheral participation. Cambridge: Cambridge University Press.

Li, L. C., Grimshaw, J. M., Nielsen, C., Judd, M., Coyte, P. C., \& Graham, I. D. (2009). Evolution of Wenger's concept of community of practice. Implementation Science, 4(1), 11 .

Lin, Y. L., \& Kao, C. H. (2016). A Study on the policy of sport for all in Taiwan from the perspective of the new public service. Asian Sports Management Review, $10,2-10$.

Lindsey, I. (2006). Local partnerships in the United Kingdom for the new opportunities for PE and sport programme: A policy network analysis. European Sport Management Quarterly, 6(2), 167-184.

Marlier, M., Van Dyck, D., Cardon, G., De Bourdeaudhuij, I., Babiak, K., \& Willem, A. (2015). Interrelation of sport participation, physical activity, social capital and mental health in disadvantaged communities: A SEM-analysis. PloS One, 10(10), 18.

Mayer, A., Woulfin, S., \& Warhol, L. (2015). Moving the center of expertise: Applying a communities of practice framework to understand coaching in urban school reform. Journal of Educational Change, 16(1), 101-123.

Meyrick, J. (2006). What is good qualitative research? A first step towards a comprehensive approach to judging rigour/quality. Journal of Health Psychology, 11(5), 799-808.

Mintzberg, H. (2009). Rebuilding companies as communities. Harvard Business Review, 87(7/8), 140-143.

Misener, K., \& Doherty, A. (2009). A case study of organizational capacity in nonprofit community sport. Journal of Sport Management, 23 (4), 457-482.

Nath, C., Huh, J., Adupa, A. K., \& Jonnalagadda, S. R. (2016). Website sharing in online health communities: A descriptive analysis. Journal of Medical Internet Research, 18(1).

Nonaka, I. (1994). A dynamic theory of organizational knowledge creation. Organization Science, 5(1), 14-37.

Phillpots, L., Grix, J., \& Quarmby, T. (2011). Centralized grassroots sport policy and 'new governance': A case study of County Sports Partnerships in the UKUnpacking the paradox. International Review for the Sociology of Sport, 46(3), 265-281.

Polanyi, M. (1962). Personal knowledge: Toward a post-critical philosophy. Chicago: University of Chicago Press.

Roberts, J. (2006). Limits to communities of practice. Journal of Management Studies, 43(3), 623-639.

Robson, C. (2011). Real world research: A resource for social scientists and practitioner-researchers (Regional Surveys of the World). Oxford: Blackwell Publishing.

Rowe, N. (2009). The active people survey: A catalyst for transforming evidence-based sport policy in England. International Journal of Sport Policy and Politics, 1(1), 89-98.

Sharpe, E. K. (2006). Resources at the grassroots of recreation: Organizational capacity and quality of experience in a community sport organization. Leisure Sciences, 28(4), 385-401.

Shaw, S., \& Hoeber, L. (2016). Unclipping our wings: Ways forward in qualitative research in sport management. Sport Management Review, 19(3), $255-265$.

Skille, E. (2008). Understanding sport clubs as sport policy implementers: A theoretical framework for the analysis of the implementation of central sport policy through local and voluntary sport organizations. International Review for the Sociology of Sport, 43(2), 181-200.

Skille, E., \& Osteras, J. (2011). What does sport mean to you? Fun and other preferences for adolescents' sport participation. Critical Public Health, 21(3), 359372 .

Sportanddev (2016). Vison, mission, goals. Retrieved from. http://www.sportanddev.org/en/about this platform/vision mission goals22/.

Stoszkowski, J., \& Collins, D. (2014). Communities of practice, social learning and networks: Exploiting the social side of coach development. Sport, Education and Society, 19(6), 773-788.

Stoszkowski, J., \& Collins, D. (2016). Sources, topics and use of knowledge by coaches. Journal of Sports Sciences, 34(9).

Tracy, S. J. (2010). Qualitative quality: Eight "big-tent" criteria for excellent qualitative research. Qualitative Inquiry, 16(10), 837-851.

Van Tuyckom, C., \& Scheerder, J. (2010). Sport for all? Insight into stratification and compensation mechanisms of sporting activity in the 27 European Union member states. Sport, Education and Society, 15(4), 495-512.

Vos, S., Breesch, D., Késenne, S., Van Hoecke, J., Vanreusel, B., \& Scheerder (2011). Governmental subsidies and coercive pressures: Evidence from sport clubs and their resource dependencies. European Journal for Sport and Society, 8(4), 257-280.

Wenger, E. (1998). Communities of practice: Learning, meaning and identity. Cambridge: Cambridge University Press.

Wenger, E. (2000). Communities of practice and social learning systems. Organization, 7(2), 225-246.

Wenger, E. (2010). Communities of practice and social learning systems: The career of a concept. Social learning and communitities of practice. London: Springer, 179-198.

Wenger, E. C., \& Snyder, W. M. (2000). Communities of practice: The organizational frontier. Harvard Business Review139-145. (January-February).

Wenger, E., \& Trayner, B. (2013). International Platform on Sport \& Development: A strategic review, report. 47.

Wenger, E., McDermott, R. A., \& Snyder, W. (2002). Cultivating communities of practice: A guide to managing knowledge. Harvard Business Press.

Williams, P. (2002). The competent boundary spanner. Public Administration, 8o(1), 103-124.

Yin, R. (2017). Case study research and applications: Design and methods. London: Sage publications. 